\title{
Chromatin proteins and RNA are associated with DNA during all phases of mitosis
}

\author{
Kathryn L Black ${ }^{1}$, Svetlana Petruk ${ }^{1}$, Tyler K Fenstermaker ${ }^{1}$, Jacob W Hodgson ${ }^{2}$, Jeffrey L Caplan ${ }^{3}$, \\ Hugh W Brock ${ }^{2}$, Alexander Mazo ${ }^{1}$ \\ ${ }^{1}$ Department of Biochemistry and Molecular Biology and Kimmel Cancer Center, Thomas Jefferson University, Philadelphia, \\ PA, USA; ${ }^{2}$ Department of Zoology, University of British Columbia, Vancouver, BC, Canada; ${ }^{3}$ Delaware Biotechnology Institute \\ Bio-Imaging Center, University of Delaware, Newark, DE, USA
}

Mitosis brings about major changes to chromosome and nuclear structure. We used recently developed proximity ligation assay-based techniques to investigate the association with DNA of chromatin-associated proteins and RNAs in Drosophila embryos during mitosis. All groups of tested proteins, histone-modifying and chromatin-remodeling proteins and methylated histones remained in close proximity to DNA during all phases of mitosis. We also found that RNA transcripts are associated with DNA during all stages of mitosis. Reduction of H3K27me3 levels or elimination of RNAs had no effect on the association of the components of PcG and TrxG complexes to DNA. Using a combination of proximity ligation assay-based techniques and super-resolution microscopy, we found that the number of protein-DNA and RNA-DNA foci undergoes significant reduction during mitosis, suggesting that mitosis may be accompanied by structural re-arrangement or compaction of specific chromatin domains.

Keywords: chromatin; epigenetics; mitosis; PcG; TrxG

Cell Discovery (2016) 2, 16038; doi:10.1038/celldisc.2016.38; published online 25 October 2016

\section{Introduction}

DNA replication [1, 2] and mitosis [3-5] are the two phases of the cell cycle during which epigenetic marks must be inherited. Although mitosis is characterized by increased chromosome condensation, the accompanying molecular mechanisms are poorly understood at the chromatin level. A recent study assaying genomewide DNase I accessibility (Hsiung et al. [6] and references therein) suggests that changes during mitosis are gene-specific and favor promoter proximal regions and that chromatin compacts 2-3-fold during mitosis. Mitosis is accompanied by genome-wide cessation of transcription [7] at early mitotic stages [8] and is associated with global phosphorylation of transcription factors and histone $\mathrm{H} 3$ (H3Thr3 and H3Ser10) [9, 10], as well as deacetylation of histones [11].

Correspondence: Alexander Mazo

Tel: +1 215503 4785; Fax: 215-503-8166;

E-mail: Alexander.Mazo@jefferson.edu

Received 20 June 2016; accepted 7 October 2016
Epigenetic bookmarking during mitosis is thought to include modified histones, histone modifiers, nucleosome remodeling and transcriptional machineries, transcription factors and non-coding (nc) RNAs [12-15]. Some of these proteins dissociate during all or some stages of mitosis, while others remain on mitotic chromosomes. Until recently, the fate of transcripts during mitosis was unknown. However, we showed that in human lymphoblast cells RNAs are stable through all stages of mitosis [16].

The current methods for studying association of proteins with chromosomes in mitosis are limited to two major approaches: immunofluorescence (IF) detection of colocalization of proteins with DNA and chromatin immunoprecipitation (ChIP) assays [17]. Although IF can detect proteins at all mitotic stages, ChIP studies are limited to early stages, as they use cells synchronized at early mitotic stages with inhibitors of microtubule formation. The divergence in the IF-based experimental results for chromosome association during mitosis is especially marked for the PcG and TrxG proteins that are required for maintenance of gene repression and activation, respectively, during 
development [18]. They regulate their target genes by binding to promoter proximal regions or to promoter distal sites termed PcG response elements and TrxG response elements, respectively [19]. They function at these sites as protein complexes of chromatinremodeling factors, histone-modifying enzymes or polynucleosome compaction factors [20] in modulating chromatin structure.

Paradoxically, most PcG proteins dissociate at metaphase, during which maximal chromosome condensation occurs. IF and ChIP assays using Drosophila cell lines suggested retention of $\mathrm{PcG}$ proteins PSC, PC and dRING/SCE on mitotic chromosomes, although the levels of these proteins were lower compared with their association with interphase DNA [5]. Similarly, IF analysis of mammalian cells detected association of $\mathrm{PcG}$ proteins SUZ12 and EZH2 and histone H3K27me3 with mitotic chromosomes [21]. In contrast, Buchenau et al. [3] showed a loss of PC and reduced PSC by IF in Drosophila embryos. The re-association of $\mathrm{PcG}$ proteins with decondensed chromosomes at anaphase/telophase was suggested to result from re-assembly of PcG complexes [3].

During mitosis, some $\operatorname{TrxG}$ proteins remain associated with condensed chromosomes and may be retained for gene activation in telophase or upon exit from mitosis [13, 22]. Analysis of association of TrxG proteins with mitotic chromosomes is also controversial: while some IF studies detected MLL1 on mitotic chromosomes [13, 23, 24], Mishra et al. [25] showed that MLL1 is displaced during mitosis. Using ChIP assays, Blobel et al. [13] found that while MLL1 associates with mitotic DNA, other TrxG proteins, H3K4 histone methyltransferases (HMTs) MLL2, SETD1, ASH2L and H3K4 demethylase LSD1 are displaced from chromatin during mitosis. These conflicting reports on the detectable levels of TrxG and $\mathrm{PcG}$ proteins associated with condensed chromosomes at prophase and metaphase [3, 5, 26, 27] may arise from the technical limitations of the assays, cell synchronization methods or developmental stage of the examined tissues.

Here we used two recently developed novel techniques to determine the association of chromatin proteins [28] and RNAs [16] with DNA during mitotic stages. These assays are based on the detection of proteins or RNA on DNA by proximity ligation assays (PLA). Using these assays, we show that RNAs and multiple chromatin proteins, including $\mathrm{PcG}$ and TrxG histonemodifying enzymes, chromatin-remodeling factors and major forms of methylated histones remain associated with a limited number of foci on DNA during all phases of mitosis. Furthermore, we found that H3K27me3 and RNAs are not essential for association of PcG and TrxG proteins with DNA during any stage of mitosis.

\section{Results}

Methylated histones, histone-modifying and nucleosome-remodeling proteins remain associated with DNA during all stages of mitosis

Previously we developed a PLA-based Chromatin Association Assay (CAA) that detects close proximity of a protein to 5-ethynyl-2'-deoxyuridine (EdU)labeled DNA in vivo [28]. Using CAA and other assays, we found that, in Drosophila embryos, major methylated histone forms $\mathrm{H} 3 \mathrm{~K} 27 \mathrm{me} 3$ and $\mathrm{H} 3 \mathrm{~K} 4 \mathrm{me} 3$ are replaced during replication with unmodified histone H3 [28]. Similarly, H3K4me1, H3K4me2, H3K9me3, H4R3me2, H3R 17me2 and H3K27Ac were displaced during replication and were accumulated at nascent DNA with various delays after DNA replication [29]. These results suggested that modified histones are unlikely to carry epigenetic information through DNA replication.

Here, using CAA, we asked whether modified histones are associated with DNA during mitosis. PLA has a unimolar sensitivity $\left(10^{-40} \mathrm{M}\right.$, Olink $)$ and CAA detects very close proximity $(40 \mathrm{~nm}$, Olink) of a protein to DNA. Therefore, compared with conventional IF, this method provides a direct and very sensitive approach to detect association of proteins with labeled DNA at all stages of mitosis. We used CAA in Drosophila embryos at nuclear divisions 14-16 to detect the association of proteins with DNA during mitosis. At this developmental stage, the cell cycles are very short ( $\mathrm{S}$ phase is $50 \mathrm{~min}, \mathrm{G} 2$ is from 30 to $150 \mathrm{~min}$ and $M$ is about $10 \mathrm{~min}$ ) and lack the $\mathrm{G1}$ interphase. DNA was labeled with EdU for 30 min followed by a $2 \mathrm{~h}$ chase; this allowed EdU-labeled cells to enter into mitosis. EdU was subsequently conjugated to biotin, and antibodies to biotin and tested protein were then used in PLA to examine the proximity of a protein to labeled DNA as described previously [28, 29]. Following PLA, embryos were counterstained with antibody to histone $\mathrm{H} 3$ phosphorylated at serine 10 (H3S10-p, a specific marker for mitosis) to visualize mitotic stages and with antibody to biotin to detect EdU-labeled nuclei.

Since in these experiments the cell cycle is not synchronized, and DNA in each nucleus may be labeled with EdU for varying times and at different stages of $\mathrm{S}$ phase, some EdU-labeled nuclei may lack PLA 


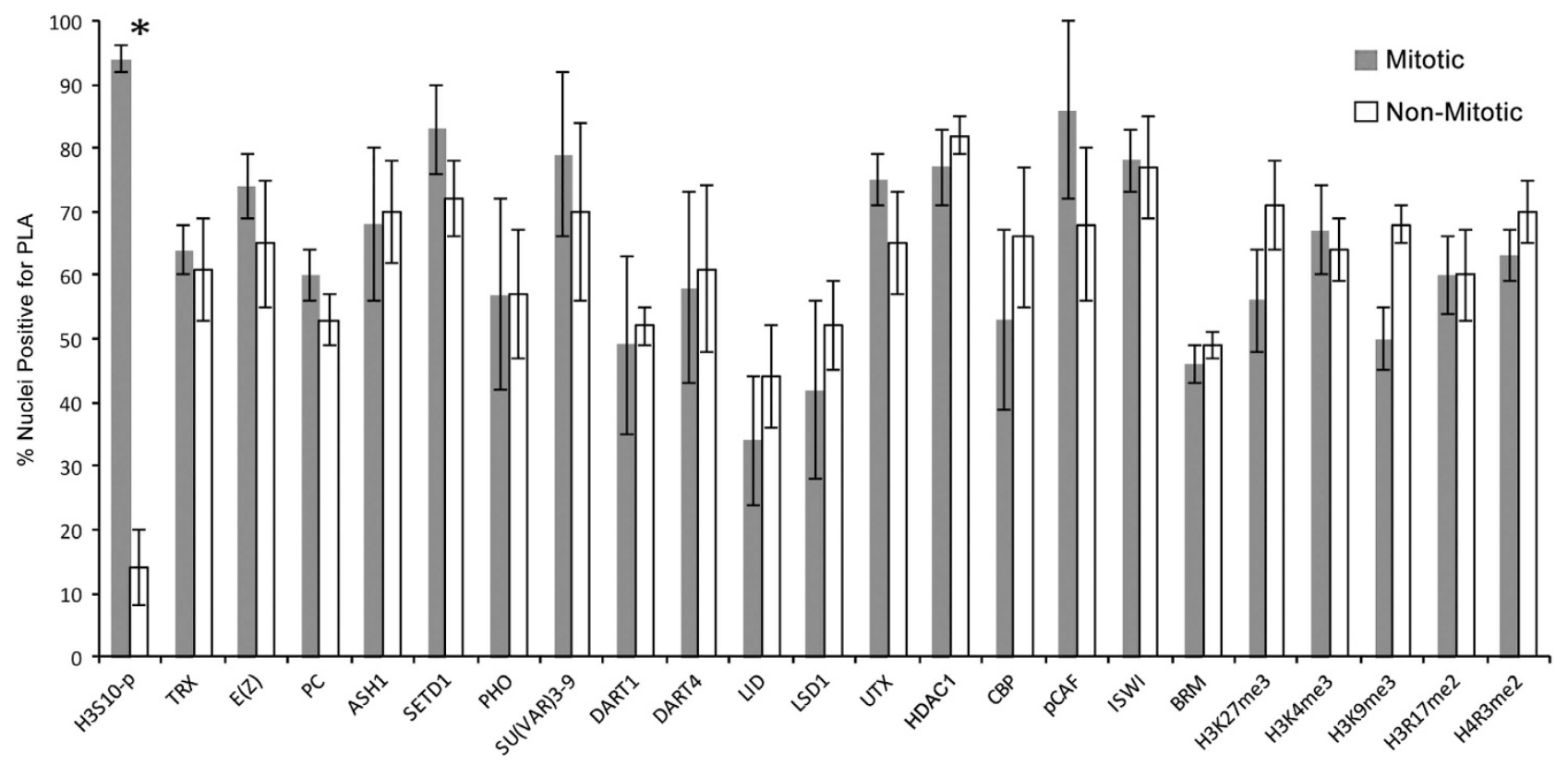

Figure 1 Comparison of association of chromosomal proteins and histones with DNA during interphase and mitosis. Statistical comparison of nuclei with positive proximity ligation assay (PLA) signals in interphase versus all stages of mitosis. All proteins/ histones tested, except H3S10-p ( ${ }^{*} P<0.05$ determined by two-tailed independent $t$-test), have similar association with DNA during all phases of mitosis. Note: For HP1 and OSA (presented in Figure $2 \mathrm{c}$ and $\mathrm{d}$ ), we were unable to accurately quantify the percentages of PLA-positive nuclei in mitosis versus interphase nuclei because their antibodies are from the same species as antibody to the mitotic marker H3S10-p. Error bars represent s.d.

signals. Therefore, to quantify potential changes in association of these proteins with DNA during mitosis, we compared the total number of EdU-labeled nuclei with the number of EdU-labeled nuclei positive for PLA signals on interphase and mitotic chromosomes. All tested modified histones and chromosomal proteins were detected with similar efficiency during interphase and mitosis (Figure 1). In control experiments, PLA signals between a mitotic marker H3S10-p and EdU-labeled DNA are detected at all stages of mitosis but were only occasionally detected in the interphase nuclei (Figures 1 and $2 \mathrm{a}$ and Table 1).

The quantification of the results of these experiments for the interphase and mitotic phases is presented in Table 1 and images for representative groups of proteins are shown in Figure $2 \mathrm{a}-\mathrm{d}$. Our results suggest that major methylated histones forms, H3K27me3, H3K4me3, H3K9me3, H4R3me2 and H3R17me2, which are associated with EdU-labeled DNA in interphase, remain associated with DNA at all four stages of mitosis. These results are in contrast to the absence of these histone forms using CAA during early stages of DNA replication $[28,29]$ and suggest that methylated histones may have an epigenetic role during mitosis.

With the exception of the H3K4 HMT ASH1 and H3K9 HMT SU(VAR)3-9, all other tested histone-modifying proteins were detected in close proximity to the replication complex and on short nascent DNA $[28,29]$. Here we found that TrxG proteins, lysine HMTs TRX, ASH1, and SETD1; the PcG proteins PHO, PC and lysine HMT E(Z); and suppressor of variegation H3K9 HMT SU(VAR)3-9, as well as the arginine HMTs DART1 and DART4, remain associated with DNA during all stages of mitosis (Figures 1 and $2 \mathrm{~b}$ and Table 1 ). We found that the lysine demethylases LID, LSD1 and UTX, which counteract the activities of lysine HMTs, are also stably associated with DNA in mitosis. Similarly, other groups of histone-modifying enzymes, histone acetyltransferases CBP and PCAF and histone deacetylase HDAC1, were also found to be stably associated with mitotic DNA (Figure 1 and Table 1).

TrxG proteins BRM, OSA and ISWI are components of six major chromatin-remodeling complexes. Our previous CAA-based data suggested that these proteins are displaced from DNA during replication and are recruited back from $10 \mathrm{~min}$ to $2 \mathrm{~h}$ after replication [29]. In contrast, we found that all these proteins are associated with mitotic chromosomes during all stages of mitosis (Figures 1 and $2 \mathrm{c}$ and Table 1). Thus all tested histone-modifying enzymes and chromatin-remodeling complexes, including 

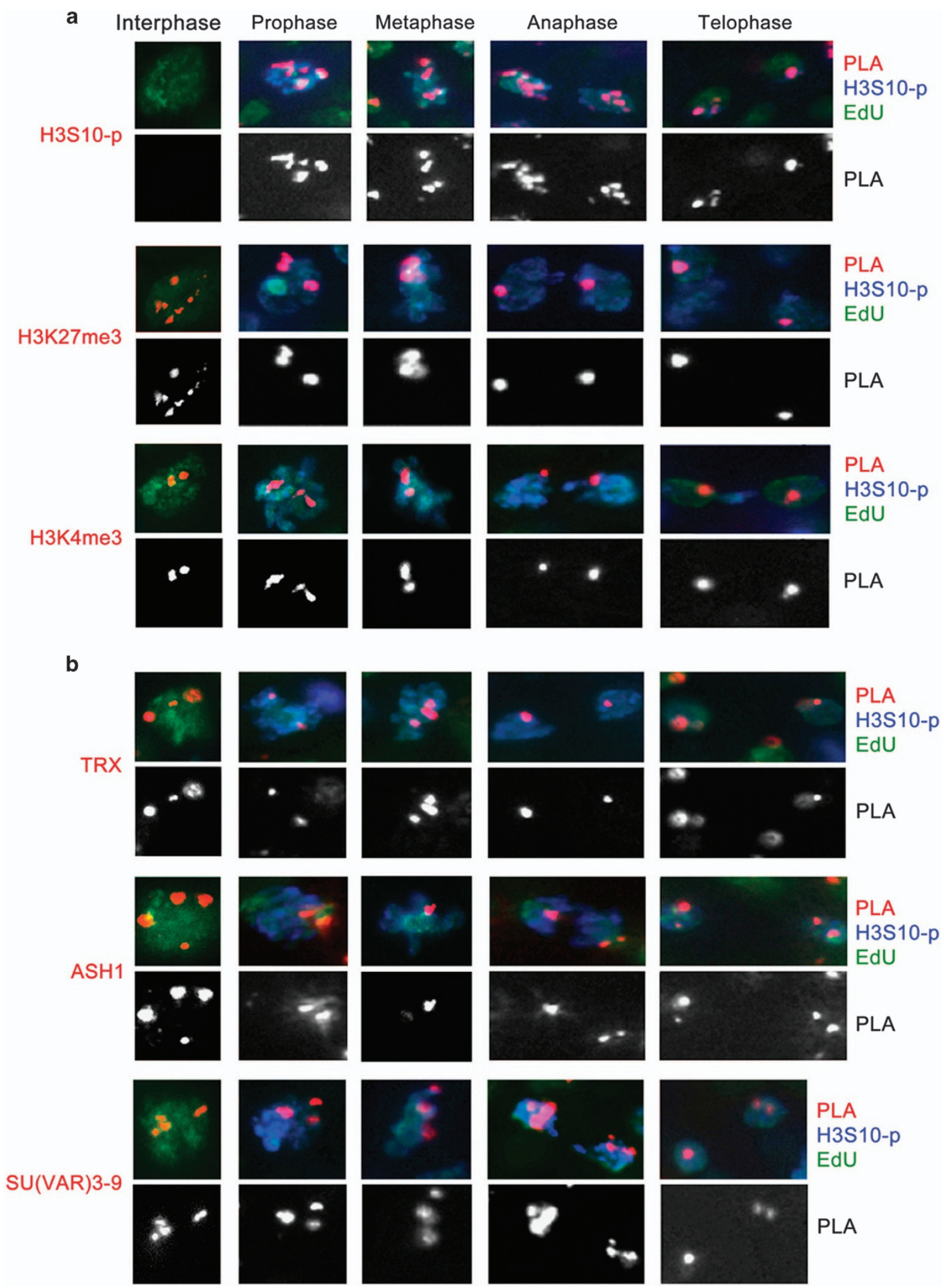

Figure 2 Modified histones, histone-modifying enzymes and histone-remodeling proteins are associated with DNA during mitosis. Proximity of the modified histones H3S10-p, H3K27me3, H3K4me3 (a), TRX, ASH1, SU(VAR)3-9 (b), ISWI, OSA, BRM (c) and HP1 (d) to DNA during interphase and all phases of mitosis was tested by Chromatin Association Assay. Proximity ligation assay (PLA), red; H3S10-p, blue; 5-ethynyl-2'-deoxyuridine (EdU), green. H3S10-p is a marker for mitosis and serves as a positive control. Note: As antibodies against HP1 and OSA are from the same species (mouse) as antibody to H3S10-p, H3S10-p marker was not used in these experiments. PLA, red; H3S10-p, blue; EdU, green. PLA signals only are shown in the bottom black and white panels. 
c

ISWI
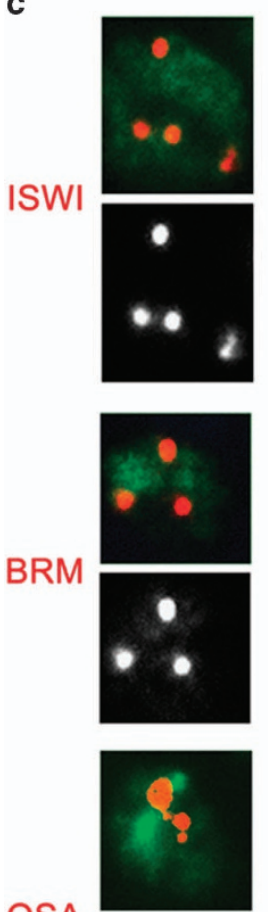

OSA

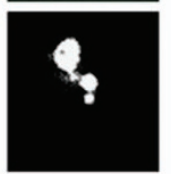

d

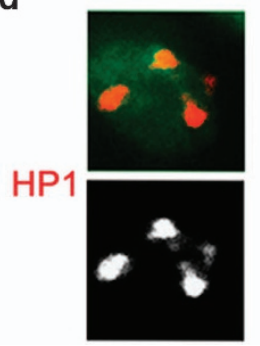

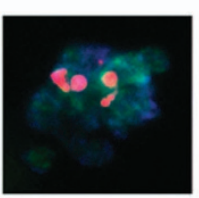
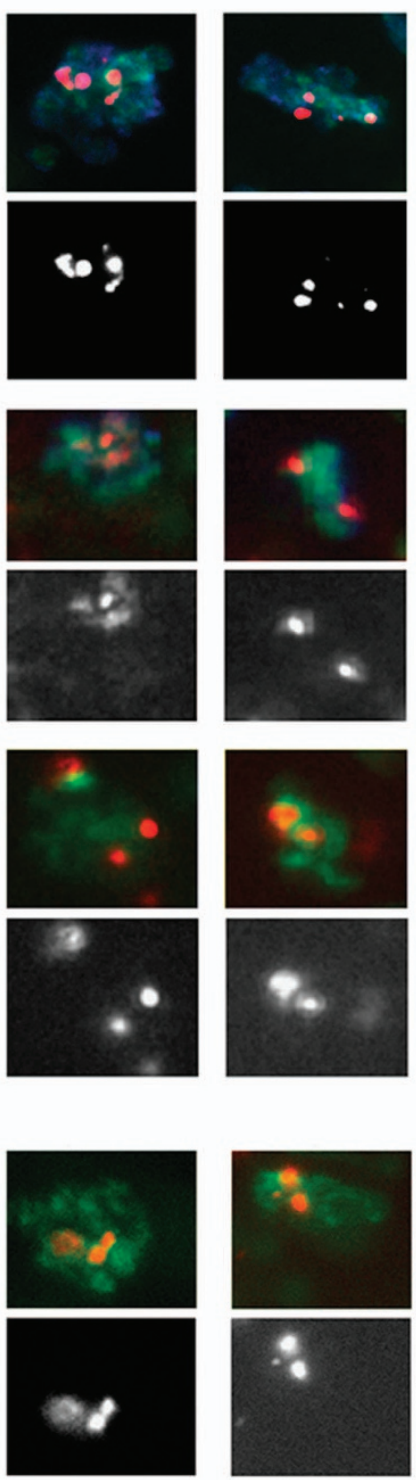
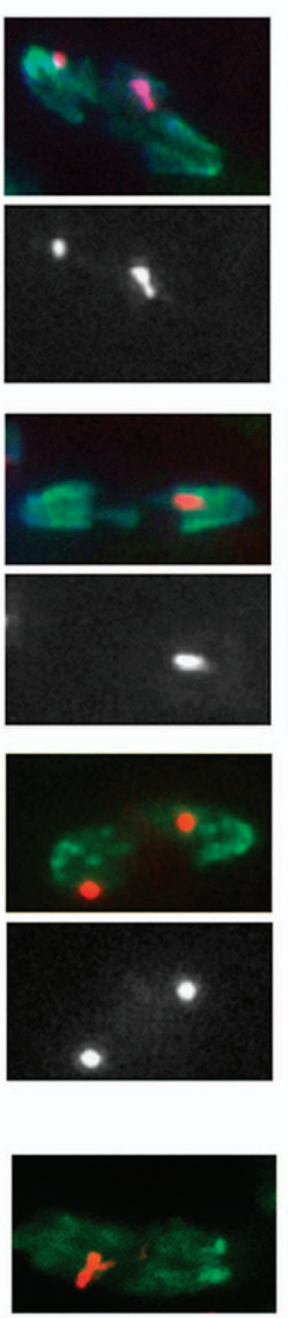
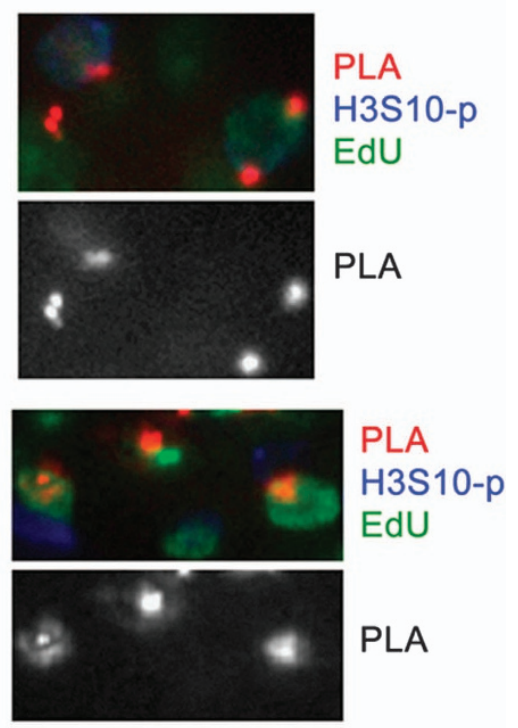

PLA
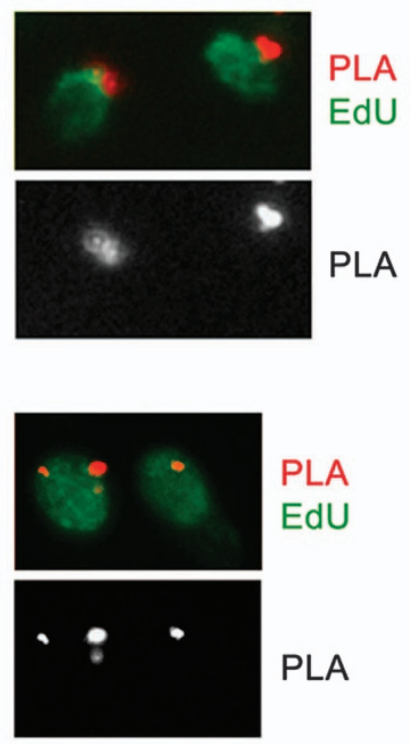

Figure 2 Continued.

ASH1, SU(VAR)3-9, BRM, OSA and ISWI, that are dissociated from DNA during replication are stably associated with DNA during mitosis.

\section{The number of protein-DNA foci decreases at late stages of mitosis}

For most of the examined proteins, we detected a relatively low number of PLA signals on interphase and mitotic chromosomes; moreover, only a few signals are detected at later stages of mitosis. One explanation may be steric hindrance that leads to epitope masking, especially owing to condensation of chromatin in mitosis, thus reducing the number of PLA signals. We tested this by performing CAA experiments following heat denaturation of nuclei in formamide and found that this treatment did not increase the number of PLA signals for H3K27me3 at any stage of mitosis (Figure 3a). We concluded that a low number of DNA-protein signals cannot be explained by low accessibility of epitopes during mitosis. Another possibility is that there is a local jackpot effect for detecting epitope interactions on mitotic chromosomes. If this were the case, then all antibodies would detect the same, limited number of foci in our CAA assay. To examine this, we performed CAA experiments with a mixture of different antibodies to proteins known to be members of different protein complexes. As seen in Figure 3b, mixing antibodies against chromosomal proteins or modified histones in a single experiment leads to a significant increase in the number 
Table 1 Number of PLA signals for chromosomal proteins and modified histones on labeled DNA during interphase and mitotic stages

\begin{tabular}{|c|c|c|c|c|c|}
\hline & Interphase & Prophase & Metaphase & Anaphase & Telophase \\
\hline H3S10p & ND & $6.1 \pm 2.7$ & $4.8 \pm 2.4$ & $6.3 \pm 1.8$ & $1.8 \pm 1.2$ \\
\hline TRX & $3.1 \pm 1.9$ & $1.8 \pm 0.8$ & $2.2 \pm 1.3$ & $1.6 \pm 0.9$ & $1.6 \pm 0.7$ \\
\hline $\mathrm{E}(\mathrm{Z})$ & $2.6 \pm 1.9$ & $2.1 \pm 1.1$ & $1.5 \pm 1.2$ & $1.2 \pm 0.4$ & $1.1 \pm 0.3$ \\
\hline $\mathrm{PC}$ & $2.8 \pm 1.3$ & $1.8 \pm 0.8$ & $2.0 \pm 1.0$ & $1.4 \pm 0.7$ & $1.3 \pm 0.5$ \\
\hline ASH1 & $4.3 \pm 2.0$ & $2.2 \pm 0.9$ & $1.5 \pm 1.0$ & $1.9 \pm 0.8$ & $1.3 \pm 0.4$ \\
\hline SETD1 & $4.3 \pm 1.7$ & $3.9 \pm 1.1$ & $2.4 \pm 0.9$ & $4.3 \pm 2.1$ & $1.6 \pm 0.6$ \\
\hline $\mathrm{PHO}$ & $2.2 \pm 1.2$ & $2.3 \pm 1.0$ & $1.8 \pm 0.8$ & $1.1 \pm 0.4$ & $1.4 \pm 0.7$ \\
\hline SU(VAR)3-9 & $4.0 \pm 1.8$ & $3.3 \pm 1.9$ & $1.8 \pm 1.0$ & $2.5 \pm 2.0$ & $1.4 \pm 0.6$ \\
\hline DART1 & $1.9 \pm 1.0$ & $1.3 \pm 0.5$ & $1.1 \pm 0.4$ & $1.3 \pm 0.6$ & $1.1 \pm 0.3$ \\
\hline DART4 & $2.6 \pm 1.3$ & $1.9 \pm 1.2$ & $1.5 \pm 0.6$ & $1.4 \pm 0.5$ & $1.3 \pm 0.5$ \\
\hline LID & $1.6 \pm 0.7$ & $1.1 \pm 0.4$ & $1.2 \pm 0.4$ & $1.3 \pm 0.6$ & $1.2 \pm 0.4$ \\
\hline LSD1 & $1.8 \pm 0.7$ & $1.6 \pm 0.8$ & $1.3 \pm 0.6$ & $1.0 \pm 0.0$ & $1.0 \pm 0.0$ \\
\hline UTX & $2.0 \pm 0.9$ & $2.0 \pm 1.1$ & $1.3 \pm 0.6$ & $1.3 \pm 0.5$ & $1.2 \pm 0.4$ \\
\hline HDAC1 & $3.0 \pm 1.4$ & $1.7 \pm 1.2$ & $1.3 \pm 0.5$ & $1.5 \pm 0.5$ & $1.1 \pm 0.4$ \\
\hline $\mathrm{CBP}$ & $2.3 \pm 1.2$ & $1.6 \pm 0.8$ & $1.4 \pm 0.5$ & $1.2 \pm 0.4$ & $1.6 \pm 0.7$ \\
\hline pCAF & $2.8 \pm 1.3$ & $2.1 \pm 1.1$ & $1.6 \pm 0.5$ & $1.7 \pm 1.3$ & $1.4 \pm 0.5$ \\
\hline ISWI & $4.2 \pm 2.2$ & $4.2 \pm 1.6$ & $3.3 \pm 1.7$ & $2.0 \pm 1.2$ & $1.3 \pm 0.8$ \\
\hline BRM & $2.1 \pm 1.0$ & $1.4 \pm 0.5$ & $1.6 \pm 0.5$ & $1.4 \pm 0.5$ & $1.5 \pm 0.8$ \\
\hline H3K27me3 & $4.0 \pm 2.1$ & $2.2 \pm 1.5$ & $1.2 \pm 0.5$ & $1.9 \pm 1.0$ & $1.3 \pm 0.5$ \\
\hline $\mathrm{H} 3 \mathrm{~K} 4 \mathrm{me} 3$ & $2.3 \pm 1.2$ & $2.5 \pm 1.7$ & $1.7 \pm 0.9$ & $1.9 \pm 1.0$ & $1.3 \pm 0.6$ \\
\hline H3K9me9 & $1.9 \pm 0.7$ & $1.4 \pm 0.6$ & $1.2 \pm 0.4$ & $1.1 \pm 0.3$ & $1.1 \pm 0.5$ \\
\hline H3R17me2 & $2.4 \pm 1.1$ & $1.8 \pm 1.0$ & $1.3 \pm 0.5$ & $1.2 \pm 0.4$ & $1.7 \pm 0.7$ \\
\hline H4R3me2 & $2.5 \pm 1.4$ & $1.9 \pm 1.1$ & $1.3 \pm 0.6$ & $1.2 \pm 0.4$ & $1.1 \pm 0.4$ \\
\hline
\end{tabular}

Abbreviations: ND, not determined because of the low number of PLA-positive nuclei; PLA, proximity ligation assay. The number of PLA signals (mean \pm s.d.) for each of the above proteins during interphase and each phase of mitosis were quantified in 50-200 nuclei from three independent experiments.

of PLA signals at each of the mitotic stages. Together, these results suggest that there are no technical limitations in detecting proteins through most of the regions of mitotic chromosomes by CAA.

The low number of PLA signals may also stem from the small sizes of nuclei of Drosophila embryos and the limit of resolution using conventional fluorescent microscopy. To improve the resolution of these experiments, we analyzed the association of $\mathrm{H} 3 \mathrm{~K} 27 \mathrm{me} 3$ using super-resolution structured illumination microscopy (SR-SIM) [30] in mammalian SEM cells that have much larger nuclei than Drosophila. These assays yielded a significantly larger number of PLA signals in the prophase. However, despite much higher resolution of SR-SIM, we also detected a significant decrease in the number of PLA signals at later stages of mitosis (Figure 3c). We conclude that a low number of DNA-protein signals for a particular protein may reflect condensation of mitotic chromatin or some previously unrecognized features of mitotic chromosomes.
Loss of H3K27 trimethylation does not affect the association of $\mathrm{PRCl}$ or PRC2 with DNA

It was proposed that $\mathrm{H} 3 \mathrm{~K} 27 \mathrm{me} 3$ is essential for association of $\mathrm{PcG} \mathrm{PRC} 1$ and $\mathrm{PRC} 2$ complexes following replication and mitosis $[1,31]$. To determine whether the level of $\mathrm{H} 3 \mathrm{~K} 27 \mathrm{me} 3$ affects the stable association of PRC2 and PRC1 subunits during mitosis, embryos were treated with the inhibitor of the only Drosophila H3K27me3 HMT E(Z), GSK343 [32, 33]. Treatment with GSK343 caused a significant decrease in the amount of nuclear H3K27me3 (Figure 4a). In control experiments, no difference in the amount of $\mathrm{H} 3 \mathrm{~K} 4 \mathrm{me} 3$ was observed between treated and nontreated embryos, confirming the specificity of GSK343 for $E(Z)$ (Figure $4 a)$. We also detect a marked decrease in the number of PLA signals for DNA-associated H3K27me3 in both interphase and mitotic nuclei following GSK343 treatment (Figure 4b). The reduced H3K27me3 levels did not affect the number of PLA signals for $\mathrm{PC}$ and $\mathrm{E}(\mathrm{Z})$ (components of $\mathrm{PRC} 1$ and 
a
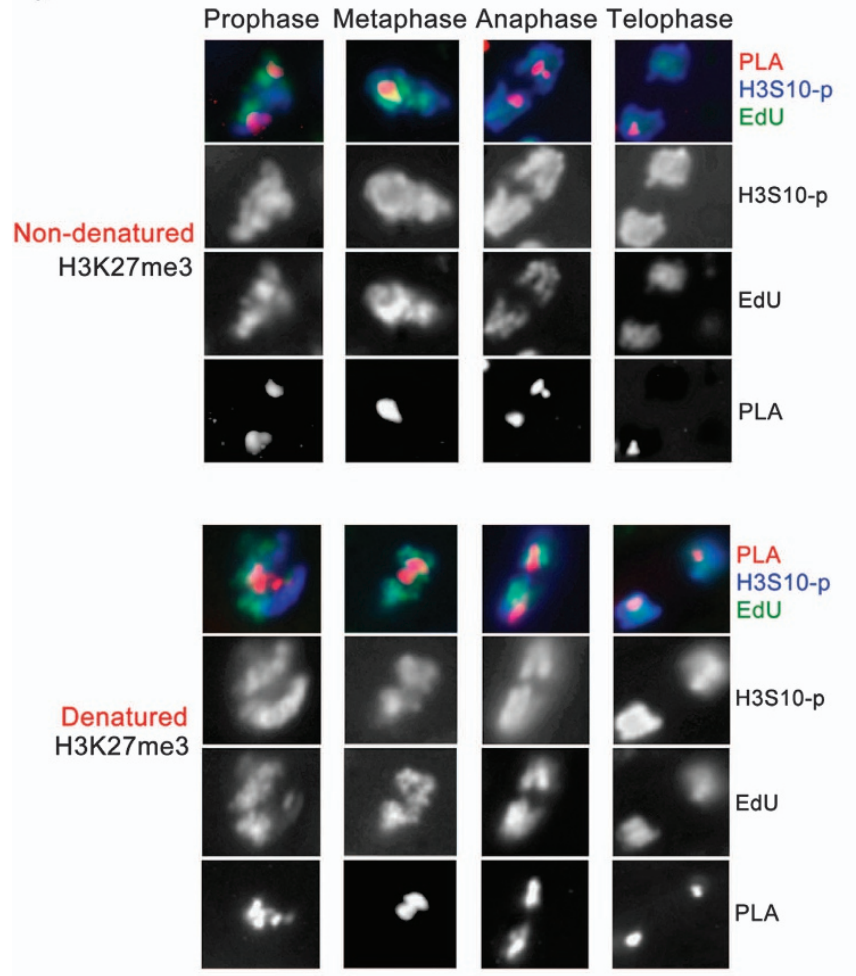

b

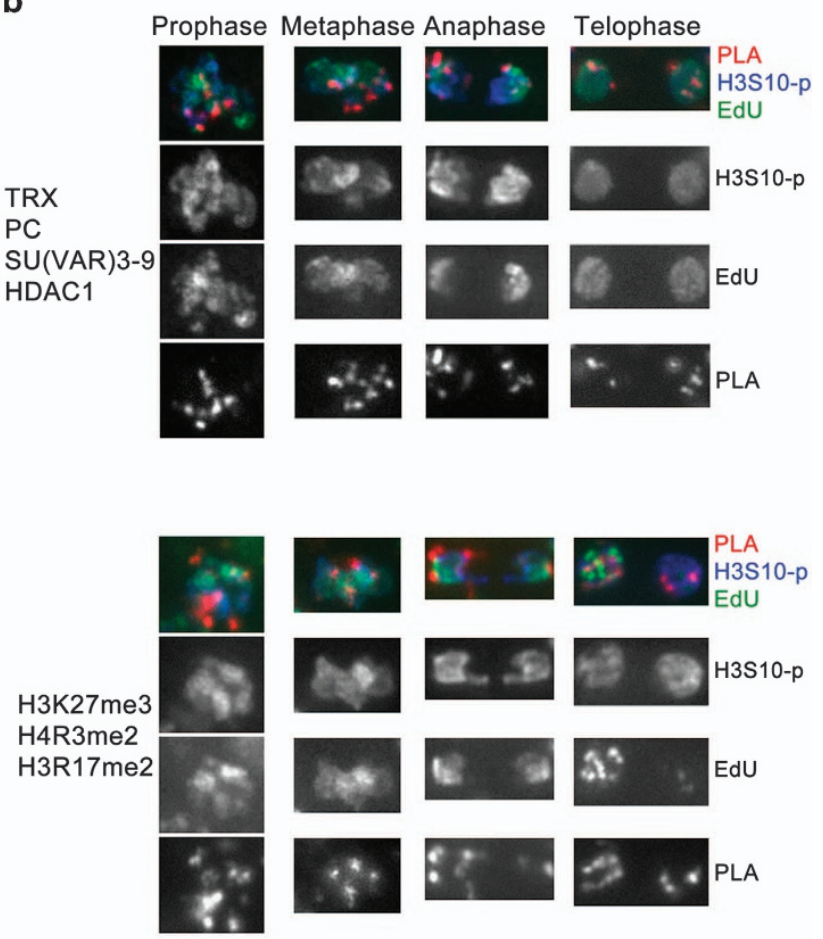

C
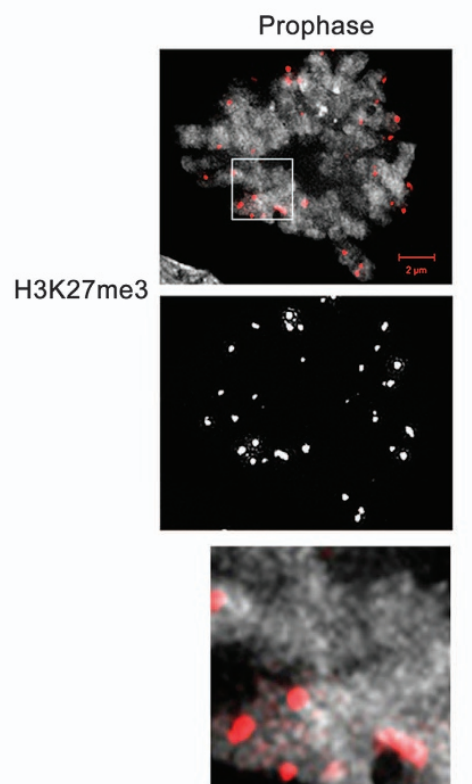

SR-SIM microscopy of SEM cells

Metaphase
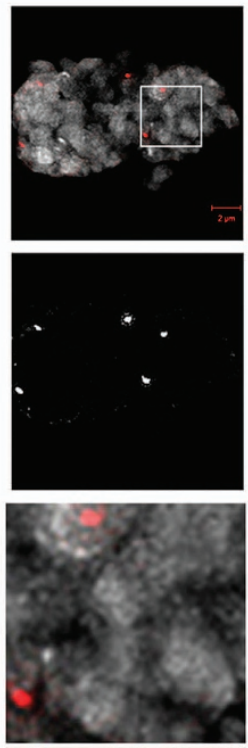

Anaphase
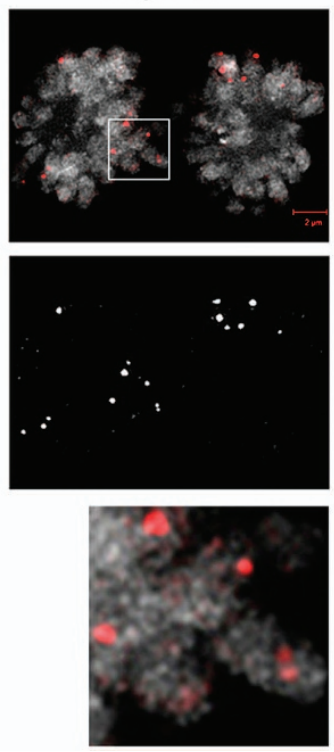

Telophase
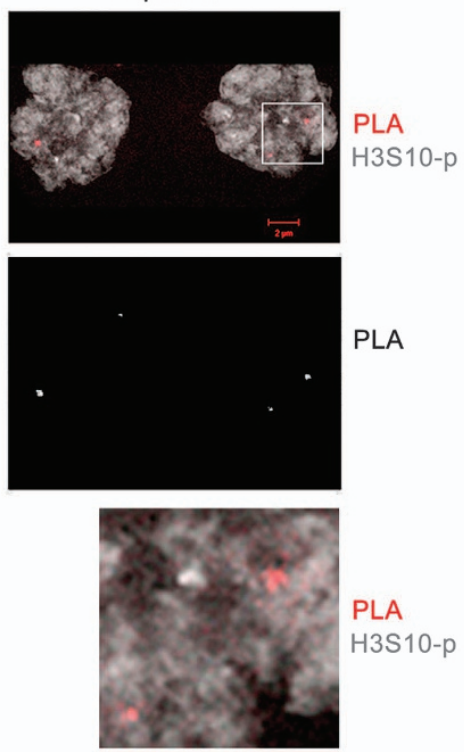

PLA H3S10-p

Figure 3 Number of protein-DNA foci decreases at late stages of mitosis. (a) Comparison of the number of proximity ligation assay (PLA) signals in Chromatin Association Assay (CAA) assays for H3K27me3 and 5-ethynyl-2'-deoxyuridine (EdU)-labeled DNA between a regular (top) and a denatured (bottom) sample. (b) CAA assays of mitotic nuclei with the indicated mixtures of chromosomal proteins (top) and modified histones (bottom). In (a and b), PLA, red; H3S10-p, blue; EdU, green. PLA signals only are shown in the bottom black and white panels. (c) Analysis of CAA in mammalian SEM cells using super-resolution microscopy (SR-SIM). Top panels, SR-SIM of the CAA assays for H3K27me3 in SEM cells. Scale bars are indicated. Middle panels, PLA signals only. Bottom panels, magnified SR-SIM images of nuclei shown in the top panels (white outline). 
a
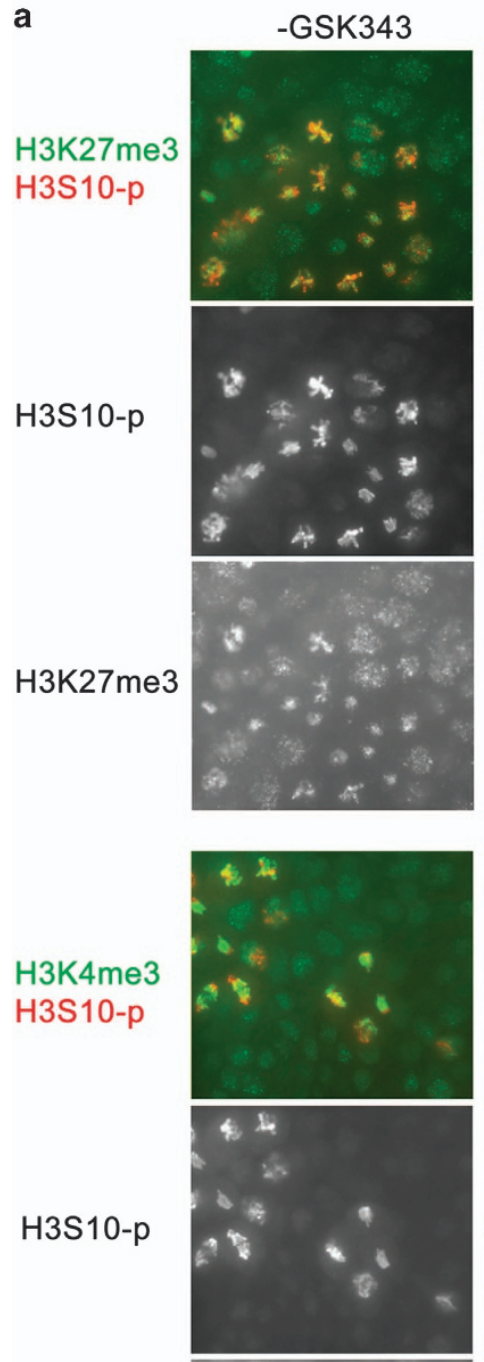

H3K4me3

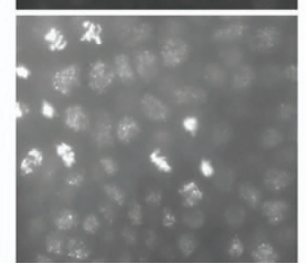

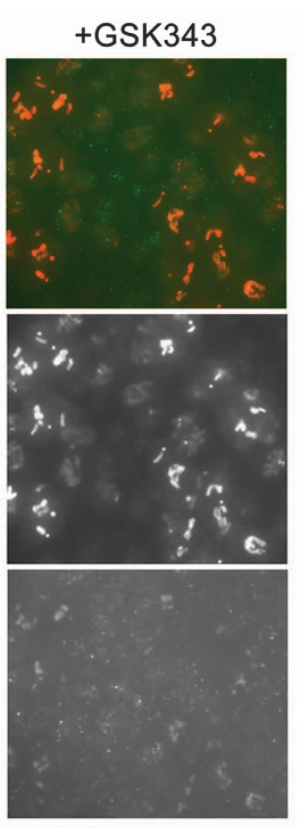
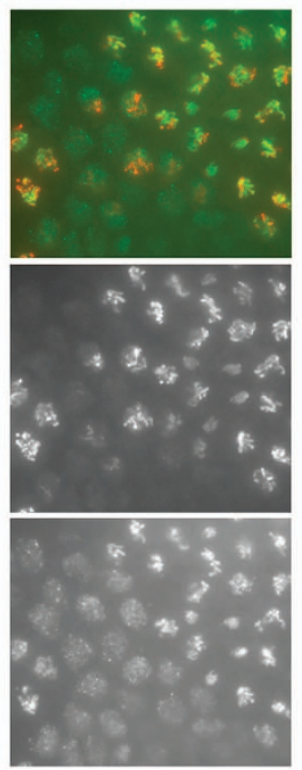

b

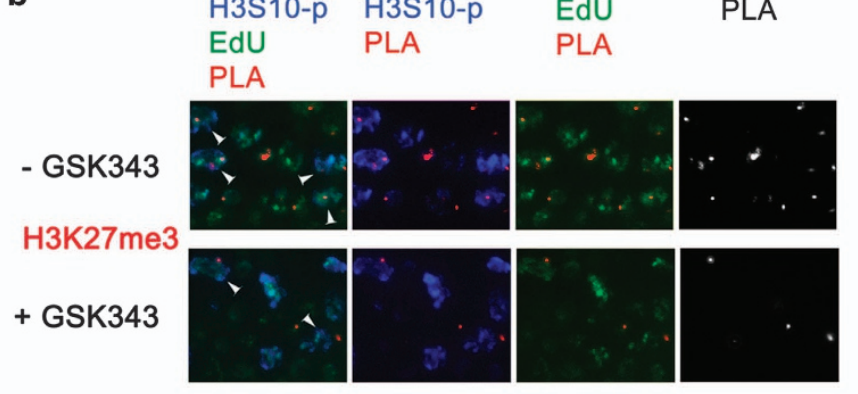

- GSK343

$E(z)$

+ GSK343
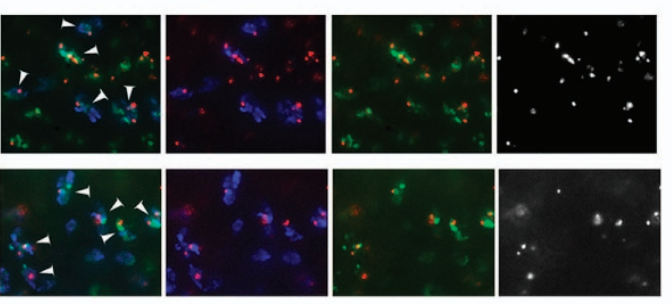

- GSK343
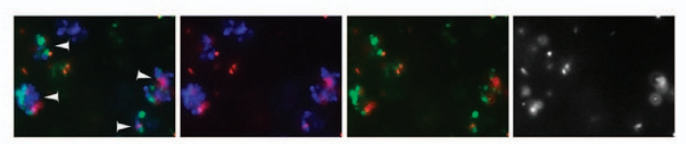

+ GSK343
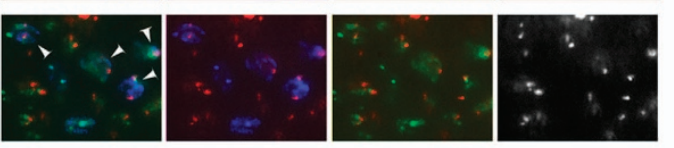

c

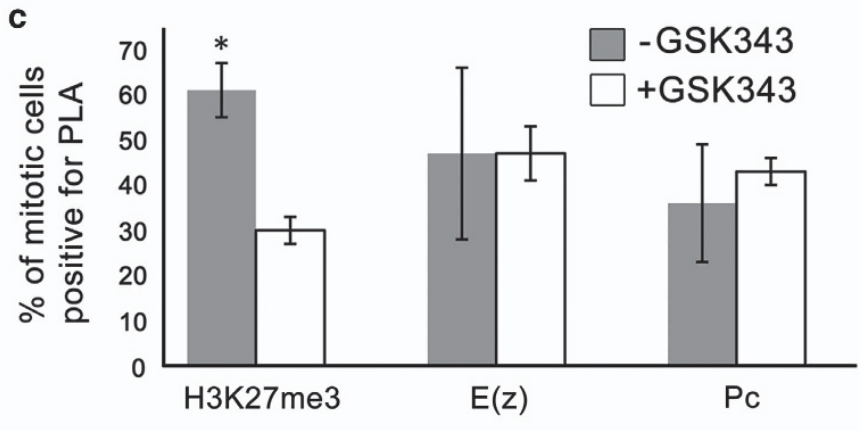

Figure 4 Reduced amount of H3K27me3 does not affect the association of E(Z) or PC with DNA. Embryos were untreated or treated with $50 \mu \mathrm{m}$ of the $\mathrm{E}(\mathrm{z})$ inhibitor GSK343. (a) Embryos were immunostained with antibodies to H3K27me3 or H3K4me3 in green and H3S10-p in red. Split channels are indicated. (b) Chromatin Association Assay was performed between H3K27me3 (top), E(z) (middle) or Pc (bottom) and biotin (5-ethynyl-2'-deoxyuridine (EdU)). Proximity ligation assay (PLA), red; H3S10-p, blue; EdU, green. White arrowheads indicate PLA-containing nuclei that are labeled with EdU and H3S10-p. Pair-wise and single split channels are indicated. (c) Quantification of the results in (b). A statistically significant difference $(P$-value $<0.05)$ is indicated by an asterisk $\left(^{*}\right)$.

PRC2, respectively) in either mitotic or interphase nuclei (Figure $4 \mathrm{~b}$ and c). Together, our results suggest that $\mathrm{H} 3 \mathrm{~K} 27 \mathrm{me} 3$ is not essential for either recruitment or association of the PcG PRC1 and PRC2 complexes during mitosis.
$R N A$ s are associated with DNA during mitosis but are not essential for binding of $P c G$ and $\operatorname{Tr} x G$ proteins

It was proposed that ncRNAs recruit PcG proteins to DNA following mitosis. However, the fate of any RNA during mitosis is unknown [34]. To assess this 
experimentally, we used the newly developed RNA-DNA Interaction Assay (RDIA) [16]. DNA in embryos was pulse-labeled with EdU for $30 \mathrm{~min}$,

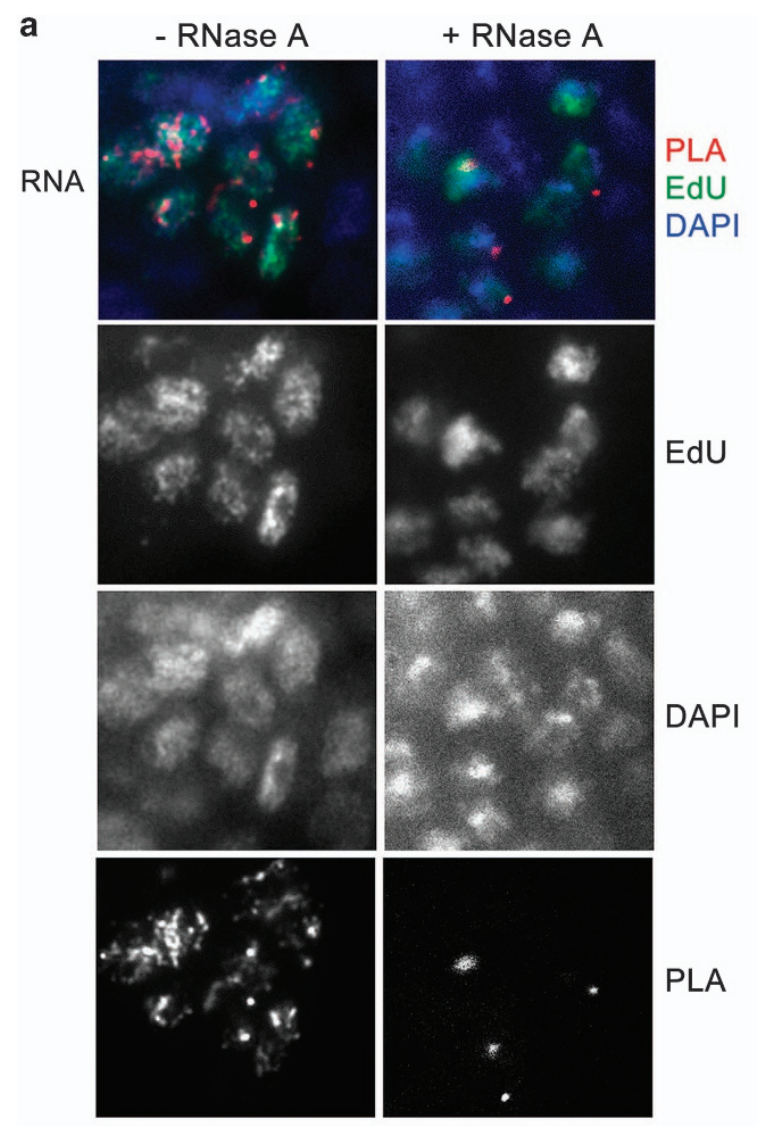

b Prophase Metaphase Anaphase Telophase

RNA

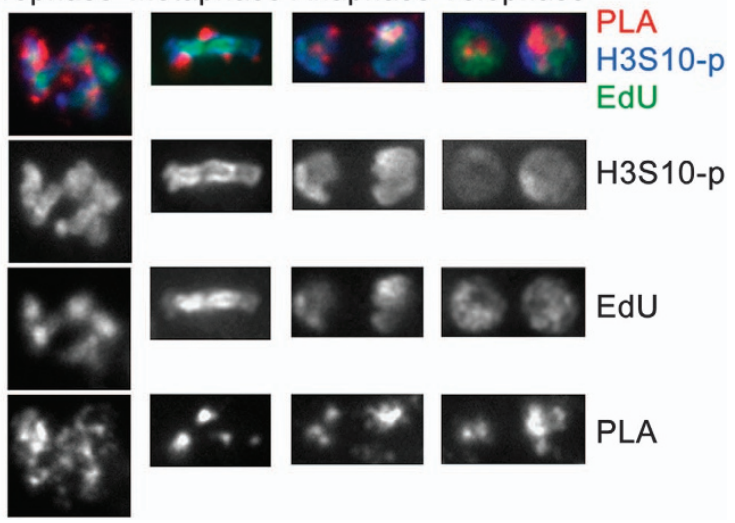

Figure 5 RNA is associated with DNA at all stages of mitosis. (a) Proximity of 5-bromouridine (BrU)-labeled RNA and 5-ethynyl-2'-deoxyuridine (EdU)-labeled DNA was assessed by RNA-DNA Interaction Assay (RDIA). Following labeling with BrU, embryos were either untreated (left) or treated (right) with RNase A. PLA, red; EdU, green; 4,6-diamidino-2-phenylindole (DAPI), blue. (b) Association of RNA with DNA at all mitotic stages was determined by RDIA. Black and white bottom panels show PLA signals only. PLA, red; EdU, green; H3S10-p, blue. chased for $1 \mathrm{~h} 40 \mathrm{~min}$ and then RNA was labeled with 5-bromouridine (BrU) for $15 \mathrm{~min}$. RNA-DNA proximity was then detected by PLA (see below and Materials and Methods). The specificity of this assay was demonstrated previously [16] and is illustrated by the fact that multiple PLA signals between RNA and DNA are detected only in nuclei that are labeled by EdU (Figure 5a). Moreover, treatment of embryos with RNase almost completely eliminates PLA signals, further suggesting that these signals are specific to labeled RNA (Figure 5a). We found that in Drosophila embryos bulk RNAs are associated with DNA during all stages of mitosis (Figure 5b), similar to human lymphoblast cells (GM22737) examined previously [16].

RNAs are unlikely to be essential for recruitment of chromosomal proteins to DNA as proposed previously (discussed in Steffen and Ringrose [34]), as our CAA results suggest that these proteins are not dissociated from DNA through all mitotic stages. Nevertheless, the presence of RNA at mitotic chromosomes may imply that RNAs have a role in stabilizing chromosomal proteins at DNA during this stage of the cell cycle. To test this possibility, we assessed association of the $\mathrm{PcG}$ proteins $P C$ and $E(Z)$ and the TrxG protein TRX following extensive treatment of embryos with RNase. This treatment led to complete elimination of the PLA signals between RNA and DNA (Figure 5a), suggesting that most RNAs were destroyed. However, RNase treatment had no detectable effect on association of PC, E(Z) and TRX at any mitotic stage (Figure 6). Together, these results suggest that while RNAs are associated with DNA during mitosis and may thus have a certain epigenetic role, they are unlikely to be essential for either recruitment or association of chromosomal proteins during this stage of the cell cycle.

\section{Discussion}

We used previously developed highly sensitive assays, RDIA [16] and CAA [28], to determine the association of DNA with RNA, methylated histones, chromatin-modifying enzymes and chromatinremodeling proteins during mitosis. Compared with detection of proteins by conventional IF, these methods detect RNA or proteins within very close proximity $(\leqslant 40 \mathrm{~nm})$ of DNA in intact nuclei at all stages of mitosis. RDIA is the only current method that tests the proximity of RNA and DNA in vivo at any stage of the cell cycle [16].

A common feature of our results is that the number of PLA signals is decreased 2-3-fold for all tested 


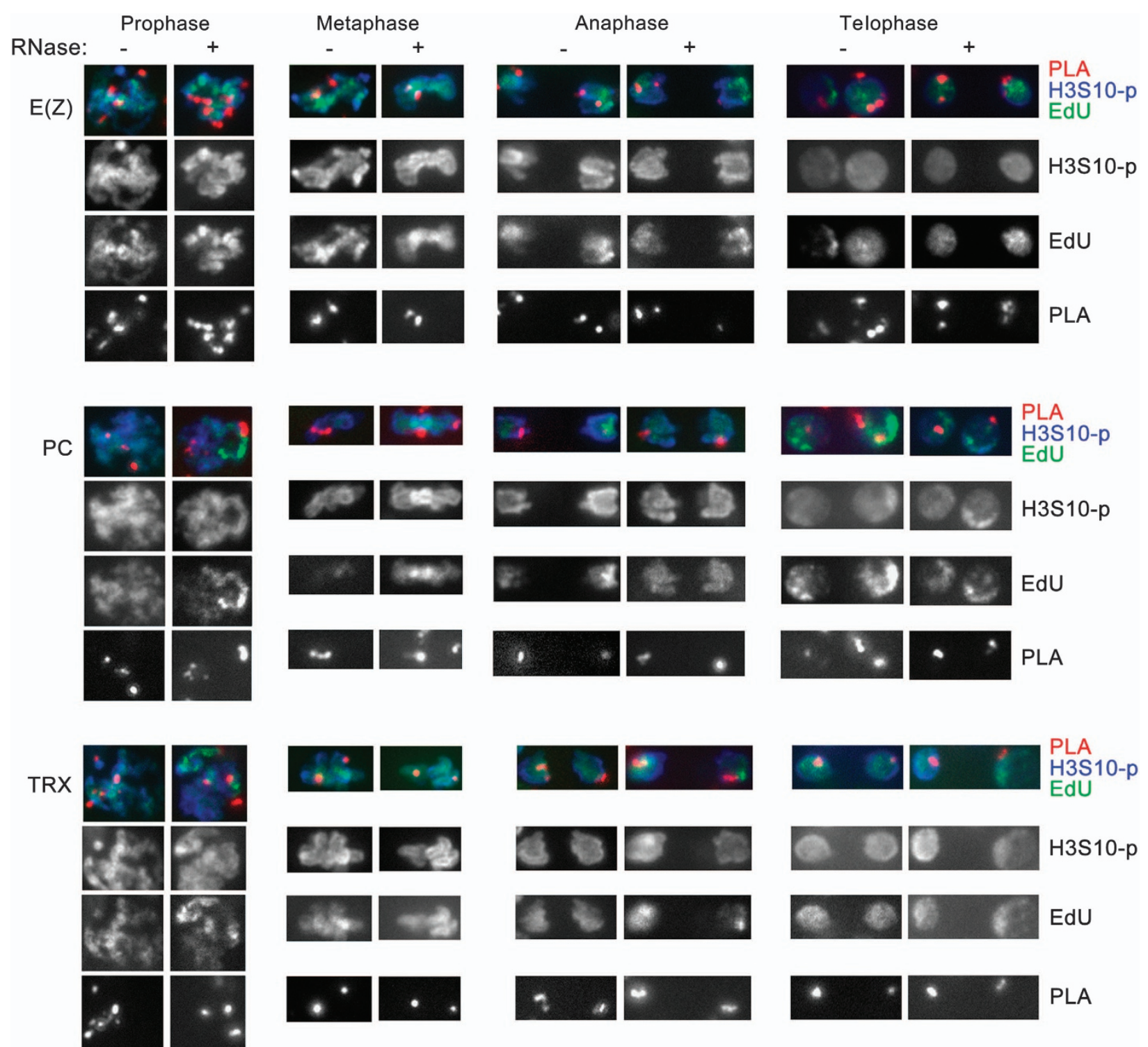

Figure 6 RNAs are not essential for association of E(Z), PC and TRX with mitotic chromosomes. Chromatin Association Assay was performed with antibodies to the indicated proteins and labeled DNA (biotin) in embryos that were either untreated (left columns) or treated with RNase A (right columns). Black and white bottom panels show proximity ligation assay (PLA) signals only. PLA, red; 5-ethynyl-2'-deoxyuridine (EdU), green; H3S10-p, blue.

proteins during later stages of mitosis. This decrease is consistent with the recently determined degree of compaction of chromatin during mitosis $[6,35,36]$. Our experiments show that these changes are not caused by low resolution of conventional microscopy, the small size of nuclei in Drosophila embryos or reduced accessibility of epitopes in condensed chromatin. Instead, these results suggest that during mitosis individual chromatin proteins may be associated with nuclear compartments, similar to organization during interphase into chromatin domains, including transcribed (transcription factories) or repressed genes (PcG bodies) [6, 37, 38]. Our results also indicate that at later stages of mitosis these chromatin domains may undergo further reorganization, which is consistent with loss of long-range chromatin interactions [39].

A major finding of this work is that bulk RNAs, methylated histones and multiple chromatin factors, including PcG and TrxG epigenetic factors, representing both histone-modifying enzymes and chromatin-remodeling complexes, remain associated with DNA during all phases of mitosis (Figures 1 and 2, 
Table 1). We previously showed that methylated histones and some histone modifiers and nucleosome remodelers are dissociated from DNA during replication $[28,29]$. However, their stable association with DNA during mitosis suggests a possible epigenetic role for these proteins and RNA during this stage of the cell cycle. These results are consistent with previous reports of transcriptional regulators that are partially or fully retained on mitotic chromatin (cited in Hsiung et al. [6]). Our findings strongly suggest that the stable DNA association of RNA, methylated histones and PcG- and TrxG-modifying and -remodeling enzymes during all stages of mitosis provides a mechanism for very complete conservation of most of the chromosomal proteins and RNA content in mitosis.

There is disagreement in the literature on PcG and TrxG protein association with mitotic chromosomes during Drosophila embryogenesis. One potential cause is developmental or cell-specific changes in the stability of these factors on chromosomes during mitosis. In preblastoderm embryos, EGFP (enhanced green fluorescent protein)-fusion proteins of $\mathrm{PcG}$ proteins $\mathrm{E}$ (Z), PHO and PC or endogenous Polyhomeotic [26, 40] were dissociated from chromosomes. However, there was detectable association with EGFP-fusion proteins of TrxG proteins TRX and ASH1 but not of OSA. In gastrulating embryos, Buchenau et al. [3] reported chromosome association of $\mathrm{PcG}$ proteins PSC and Polyhomeotic but not PC at metaphase followed by detection of all three proteins at anaphase. By contrast, our results on gastrulating embryos (Figures 1 and 2 and Table 1) show that all PcG and TrxG proteins remain stably associated with DNA at all stages of mitosis.

It is also possible that differences in the results stem from using differentiated S2 cells, which exit mitosis into the G1 phase, as opposed to cells of gastrulating embryos, which have no G1, and exit mitosis into the S phase. IF studies using Drosophila S2 cells derived from a primary culture of 20-24 h-old embryos [41] showed a difference in association between subunits of the PcG complexes, PRC1 and PRC2 [5]. The PRC1 subunits PSC, PC and dRING/SCE remain associated with chromosomes during all phases of mitosis while the PRC2 subunit $E(Z)$ decreases during metaphase. In addition, similar results were obtained by ChIP-seq analysis of S2 cells arrested in mitosis [5]. We find no differences in DNA association between PRC1 and PRC2 subunits (Figure 1 and Table 1).

Other technical differences may also explain the discrepancies of our results with the literature, as the results of the previous IF studies suggest that HDAC1 dissociates from chromosomes at early mitotic stages and re-associates at late telophase [42, 43]. IF methods, even when advanced statistical analysis and confocal microscopy are used, can only show colocalization of antibody staining with 4,6-diamidino-2-phenylindole (DAPI) or mitotic markers, while CAA provides a direct assay of very close proximity, $\leqslant 40 \mathrm{~nm}$, of a protein and DNA. Furthermore, IF sensitivity is relatively low compared with the single-molecule sensitivity of CAA. The advantage of the ChIP assays is that they provide a direct test of the association of proteins with specific genomic loci. However, isolation of mitotic chromatin requires use of colcemid or nocodazole, which arrest cells in metaphase by disrupting microtubule assembly in condensed chromosomes [44]. Moreover, nocodazole-inhibited cells are not well synchronized [45], so ChIP analysis of protein binding is limited to prophase and metaphase and may potentially contain some G2 phase cells. Thus use of nocodazole may explain some differences in the modes of PRC1 and PRC2 subunit association with DNA during mitosis detected in this work and by others [5].

Similar to the previous reports $[13,25]$, we found that major modified histone forms are associated with DNA during all stages of mitosis. It has been proposed that histone modifications serve as platforms for protein recruitment or displacement during mitosis [31]. However, our results for H3K27me3 do not support this view. Subunits of PRC1 (PC) and PRC2 (E(Z)) complexes that recognize $\mathrm{H} 3 \mathrm{~K} 27 \mathrm{me} 3$ are not displaced upon reduction of $\mathrm{H} 3 \mathrm{~K} 27 \mathrm{me} 3$ levels by inhibition of the $\mathrm{E}(\mathrm{Z}) \mathrm{HMT}$ activity (Figure 4$)$. Therefore, modified histone H3K27me3 is not essential for stable association of the $\mathrm{PcG}$ proteins $\mathrm{PC}$ and $\mathrm{E}(\mathrm{Z})$ on mitotic chromosomes. Moreover, we found that histonemodifying proteins and modified histones are associated with DNA during mitosis (Figures 1 and 2 and Table 1), suggesting that both types of proteins may have separate epigenetic role(s) during cell transition through mitosis. The role of modified histones is not related, however, to the stability or recruitment of histone-modifying proteins to postmitotic chromosomes as $\mathrm{PC}$ and $\mathrm{E}(\mathrm{Z})$ do not dissociate during mitosis.

We are not aware of any previous reports of the fate of RNAs during mitosis. Using a new method, RDIA, we found that in Drosophila embryos and in cultured mammalian cells [16] RNAs synthesized prior to mitosis remain in close proximity to DNA at all mitotic stages. Similar to proteins, compaction of chromatin during mitosis also reduces the number of RNA-DNA foci, suggesting major changes in the arrangement of specific chromatin domains during mitosis. The role of 
RNAs on mitotic chromosomes may be stabilization of proteins during chromosome condensation in mitosis. However, our results suggest that RNAs are not essential for association of PcG and TrxG proteins during mitosis (Figure 6). We conclude that proteins and RNAs are independently associated with DNA during mitotic stages. Together, our results suggest a possibility that association of transcripts and many essential chromosomal proteins on mitotic chromosomes may represent molecular bookmarking during mitosis required for inheritance of transcriptional states.

\section{Materials and Methods}

\section{Analysis of protein-DNA association during mitotic stages in embryos (CAA)}

Developmentally staged embryos were dechorionated in 50\% bleach and permeabilized in octane. Nascent DNA was pulse labeled with $300 \mu \mathrm{m}$ EdU in Schneider Drosophila Medium for 30 min followed by a $2 \mathrm{~h}$ chase (to label DNA in mitotic phase of the cell cycle). Embryos were washed and fixed in 1:1 mixture of $4 \%$ formaldehyde and heptane. EdU-labeled embryos were subjected to Click-iT reaction to attach biotin to EdU (using Click-iT Cell Reaction Buffer Kit, Life Science Tech, Carlsbad, CA, USA). Embryos were washed and incubated with goat monoclonal anti-biotin antibody (1:1 000, Vector, Burlingame, CA, USA) and the rabbit antibody of interest. PLA reaction was performed according to manufacturer's instruction (Olink Bioscience, Uppsala, Sweden). Following incubation with primary antibodies from different species, secondary antibodies with conjugated oligonucleotides (MINUS and PLUS probes) were incubated for $1 \mathrm{~h}$. Two oligonucleotides that hybridize to the two PLA probes were added, and DNA ligase joins them into a closed circle if they are in close proximity (up to $40 \mathrm{~nm}$ ). PCR rolling circle amplification was carried out using phi29 polymerase in the presence of Alexa Fluor 594 fluorescentlabeled oligonucleotides (far red detector probe). Mitotic chromosomes were visualized by incubation with mouse monoclonal anti-H3S10-phosphorylated antibody (1:20 000, Abcam, Cambridge, MA, USA) followed by incubation with anti-mouse antibody conjugated with Alexa Fluor 555 (1:1 000, Life Technologies, Carlsbad, CA, USA). EdU-linked biotin was detected by incubation with Alexa Fluor 488-conjugated antigoat antibody (1:1 000, Santa Cruz, Dallas, TX, USA).

\section{Analysis of RNA-DNA association during mitotic stages in embryos (RDIA)}

After embryos were dechorionated and permeabilized in octane they were labeled with $200 \mu \mathrm{M}$ EdU for 30 min followed by a chase for $1 \mathrm{~h}$ and $40 \mathrm{~min}$ in Drosophila Schneider medium. Embryos were then incubated with $2 \mathrm{~mm} \mathrm{BrU}$ (Acros Organics, Geel, Belgium) in Drosophila Schneider medium for $15 \mathrm{~min}$, washed in phosphate-buffered saline (PBS) and fixed. For RNase experiment, embryos were labeled with EdU, chased as described above and then incubated with $2 \mathrm{~mm} \mathrm{BrU}$ (Acros Organics) in Drosophila Schneider medium for 5 min and Triton was added to final concentration $0.2 \%$ for additional $10 \mathrm{~min}$ of incubation. Embryos were briefly washed in PBT and treated for 20 min with either PBS (control treatment) or $1.5 \mathrm{mg} \mathrm{ml}^{-1}$ of RNase A (Roche, Basel, Switzerland) in PBS. Embryos were fixed and incubated first with Click-iT Cell reaction cocktail (Life Science Tech) for $30 \mathrm{~min}$ and then with goat monoclonal anti-biotin antibody (1:1 000, Vector) and mouse antibromodeoxyuridine antibody (1:200, BD Bioscience, San Diego, CA, USA) overnight at $4{ }^{\circ} \mathrm{C}$. PLA assay was performed as described above. Mitotic chromosomes were visualized by incubation with rabbit anti-H3S10-phosphorylated antibody (1:800, Active Motif, Carlsbad, CA, USA) followed by incubation with anti-rabbit antibody conjugated with Alexa Fluor 555 (1:1000, Life Technologies). EdU-linked biotin was detected by incubation with Alexa Fluor 488-conjugated anti-goat antibody (1:1000, Santa Cruz).

\section{Treatment of embryos with the E(z) inhibitor GSK343}

Embryos were pulse labeled with EdU for 30 min followed by chase for $2 \mathrm{~h}$. During the entire labeling period, embryos were incubated in the medium containing $50 \mu \mathrm{M}$ of the $\mathrm{E}(\mathrm{z})$ inhibitor GSK343 (Structural Genomics Consortium, Oxford, UK) dissolved in dimethyl sulfoxide. In control experiments, embryos were incubated for the same length of time in the presence of dimethyl sulfoxide without GSK343. Embryos were washed and fixed as described above.

\section{Heat denaturation of EdU-labeled embryos}

Embryos were labeled with EdU for $30 \mathrm{~min}$ followed by chase for $2 \mathrm{~h}$. EdU-labeled embryos were conjugated with biotin-azide using the Click-iT reaction as described earlier. Embryos were washed in PBS/0.3\% Triton X-100 for $60 \mathrm{~min}$ at room temperature. They were subsequently incubated for 30 min each in PBS $/ 0.3 \%$ Triton-X buffers containing 20, 50 and $80 \%$ of Prehybridization buffer $(50 \%$ formamide $/ 4 \times \mathrm{SSC} /$ $100 \mathrm{mM} \mathrm{Na}_{2} \mathrm{HPO}_{4}, \mathrm{pH}$ 7.0/0.1\% Tween 20). After a final $30 \mathrm{~min}$ incubation in $100 \%$ Prehybridization buffer at room temprature, embryos were heated at $83{ }^{\circ} \mathrm{C}$ for $20 \mathrm{~min}$ in $100 \%$ Prehybridization buffer. Embryos were washed once in $50 \%$ formamide $/ 2 \times \mathrm{SSC} / 0.3 \%$ CHAPS buffer (prewarmed at $37^{\circ} \mathrm{C}$ ) for $1 \mathrm{~min}$, two times in $2 \times \mathrm{SSC} / 0.3 \%$ CHAPS buffer for $2 \mathrm{~min}$ and two times in PBS $/ 0.3 \%$ Triton X-100 buffer for 2 min at room temperature. [46]. Embryos were incubated with antibodies and PLA probes as described earlier.

\section{Antibodies}

The following antibodies were used (for unnamed sources, see Petruk et al. [29]: H3S10-p (1:20 000, Abcam); Trx (1:3 000); E(z) (1:2 000); Pc (1:2 000); H3K27me3 (1:4 000, Millipore, Darmstadt, Germany); H3K4me3 (1:15 000, Active Motif); H3K9me3 (1:2 000, Active Motif); H3R17me2 (1:2 000, Active Motif); H4R3me2 (1:4 000, Active Motif); PCNA (1:5 000, Abcam); ASH1 (1:1 000); dSET (1:500); LID (1:1 000); LSD (1:3 000); PHO (1:2 000); UTX (1:1 000), DART1 and DART4 (1:1 000 and 1:2 000, respectively); HDAC1 (1:2 000, Abcam); BRM (1:500); OSA and HP1 (1:3 000 and 1:5 000, respectively, Developmental Hybridoma Bank, Iowa City, IA, USA); ISWI (1:2 000, Abcam); Su(Var)3-9 (1:300, Abcam). 


\section{Microscopy and analysis of embryos}

Staged embryos were examined using fluorescence microscopy and SIM on a Zeiss ELYRA PS.1 (Carl Zeiss, Ithaca, NY, USA). SIM $z$-stacks were acquired with five rotations and five phase shifts with a $\times 63$ Plan-Apochromat $(\mathrm{NA}=1.4)$. SR-SIM reconstructions were performed using a theoretical point spread function and an affine image alignment based on a multi-speck bead alignment. Comparative wide-field images were generated from the SIM $z$-stacks before processing. Specificity of PLA was monitored by examining whether PLA signals are detected only in the EdU-labeled nuclei. Pictures were taken of several embryos from at least three independent experiments and pictures used are a representative selection. To calculate the percentages for mitotic and non-mitotic nuclei, 100 mitotic and non-mitotic nuclei from 5 different embryos for each antibody were used. A nucleus containing at least one PLA signal was counted as a positive. A two-tailed independent $t$-test was performed for each antibody's mitotic and non-mitotic data to generate a $P$-value. $P$-values $<0.05$ were considered to be significant.

\section{Conflict of Interest}

The authors declare no conflict of interest.

\section{Acknowledgements}

We thank V Orlando, N Francis, R Jones, Y Zhang, L Di Stefano, R Eisenman, J Tamkun, T Kusch, A Shilatifard and S Richard for antibodies. We thank Peter J Brown and the Structural Genomics Consortium for E(z) inhibitor. This work was supported by the following grants: NIH R01GM075141, 1R01HL127895 to AM, NIH T32GM100836 to TKF and a grant from the Canadian Institutes of Health Research to HWB. Super-resolution microscopy access was supported by grants from the NIH-NIGMS (P20 GM103446, P30 GM103519), the NSF-EPSCoR (IIA-1301765) and the State of Delaware.

\section{Author contributions}

KLB, SP, HWB and AM conceived and designed the study. KLB performed testing of binding of chromosomal proteins and RNA to mitotic nuclei. SP analyzed RNA binding to mitotic nuclei. TKF analyzed the effect of GSK343 inhibitor on histone modifications and performed statistical analysis. JWH performed analysis of protein binding to denatured DNA. JLC performed super-resolution microscopy. AM and HWB performed overall data interpretation with others and wrote the paper.

\section{References}

1 Hansen KH, Bracken AP, Pasini D et al. A model for transmission of the H3K27me3 epigenetic mark. Nat Cell Biol 2008; 10: 1291-1300.

2 Lanzuolo C, Lo Sardo F, Diamantini A, Orlando V. PcG complexes set the stage for epigenetic inheritance of gene silencing in early $\mathrm{S}$ phase before replication. PLoS Genet 2011; 7: e1002370.

3 Buchenau P, Hodgson J, Strutt H, Arndt-Jovin DJ. The distribution of polycomb-group proteins during cell division and development in Drosophila embryos: impact on models for silencing. J Cell Biol 1998; 141: 469-481.

4 Dietzel S, Niemann H, Bruckner B, Maurange C, Paro R. The nuclear distribution of Polycomb during Drosophila melanogaster development shown with a GFP fusion protein. Chromosoma 1999; 108: 83-94.

5 Follmer NE, Wani AH, Francis NJ. A polycomb group protein is retained at specific sites on chromatin in mitosis. PLoS Genet 2012; 8: e1003135.

6 Hsiung CC, Morrissey CS, Udugama M et al. Genome accessibility is widely preserved and locally modulated during mitosis. Genome Res 2015; 25: 213-225.

7 Parsons GG, Spencer CA. Mitotic repression of RNA polymerase II transcription is accompanied by release of transcription elongation complexes. Mol Cell Biol 1997; 17: 5791-5802.

8 Liang K, Woodfin AR, Slaughter BD et al. Mitotic transcriptional activation: clearance of actively engaged Pol II via transcriptional elongation control in mitosis. Mol Cell 2015; 60: 435-445.

9 Rossetto D, Avvakumov N, Cote J. Histone phosphorylation: a chromatin modification involved in diverse nuclear events. Epigenetics 2012; 7: 1098-1108.

10 Wilkins BJ, Rall NA, Ostwal Y et al. A cascade of histone modifications induces chromatin condensation in mitosis. Science 2014; 343: 77-80.

11 Cimini D, Mattiuzzo M, Torosantucci L, Degrassi F. Histone hyperacetylation in mitosis prevents sister chromatid separation and produces chromosome segregation defects. Mol Biol Cell 2003; 14: 3821-3833.

12 Zaidi SK, Young DW, Montecino MA et al. Mitotic bookmarking of genes: a novel dimension to epigenetic control. Nat Rev Genet 2010; 11: 583-589.

13 Blobel GA, Kadauke S, Wang E et al. A reconfigured pattern of MLL occupancy within mitotic chromatin promotes rapid transcriptional reactivation following mitotic exit. Mol Cell 2009; 36: 970-983.

14 Zaidi SK, Grandy RA, Lopez-Camacho C et al. Bookmarking target genes in mitosis: a shared epigenetic trait of phenotypic transcription factors and oncogenes? Cancer Res 2014; 74: 420-425.

15 Young DW, Hassan MQ, Pratap J et al. Mitotic occupancy and lineage-specific transcriptional control of rRNA genes by Runx2. Nature 2007; 445: 442-446.

16 Petruk S, Fenstermaker TK, Black KL, Brock HW, Mazo A. Detection of RNA-DNA association by a proximity ligation-based method. Sci Rep 2016; 6: 27313.

17 Kadauke S, Blobel GA. Mitotic bookmarking by transcription factors. Epigenetics Chromatin 2013; 6: 6.

18 Brock HW, Fisher CL. Maintenance of gene expression patterns. Dev Dyn 2005; 232: 633-655.

19 Simon JA, Tamkun JW. Programming off and on states in chromatin: mechanisms of Polycomb and trithorax 
group complexes. Curr Opin Genet Dev 2002; 12: 210-218.

20 Schwartz YB, Pirrotta V. A new world of Polycombs: unexpected partnerships and emerging functions. Nat Rev Genet 2013; 14: 853-864.

21 Aoto T, Saitoh N, Sakamoto Y, Watanabe S, Nakao M. Polycomb group protein-associated chromatin is reproduced in post-mitotic G1 phase and is required for S phase progression. J Biol Chem 2008; 283: 18905-18915.

22 Dey A, Nishiyama A, Karpova T, McNally J, Ozato K. Brd4 marks select genes on mitotic chromatin and directs postmitotic transcription. Mol Biol Cell 2009; 20: 4899-4909.

23 Ennas MG, Sorio C, Greim R et al. The human ALL-1/ MLL/HRX antigen is predominantly localized in the nucleus of resting and proliferating peripheral blood mononuclear cells. Cancer Res 1997; 57: 2035-2041.

24 Caslini C, Alarcon AS, Hess JL, Tanaka R, Murti KG, Biondi A. The amino terminus targets the mixed lineage leukemia (MLL) protein to the nucleolus, nuclear matrix and mitotic chromosomal scaffolds. Leukemia 2000; 14: 1898-1908.

25 Mishra BP, Ansari KI, Mandal SS. Dynamic association of MLL1, H3K 4 trimethylation with chromatin and Hox gene expression during the cell cycle. FEBS J 2009; 276: 1629-1640.

26 Steffen PA, Fonseca JP, Ganger C et al. Quantitative in vivo analysis of chromatin binding of Polycomb and Trithorax group proteins reveals retention of $\mathrm{ASH} 1$ on mitotic chromatin. Nucleic Acids Res 2013; 41: 5235-5250.

27 Fonseca JP, Steffen PA, Muller S et al. In vivo Polycomb kinetics and mitotic chromatin binding distinguish stem cells from differentiated cells. Genes Dev 2012; 26: 857-871.

28 Petruk S, Sedkov Y, Johnston DM et al. TrxG and PcG proteins but not methylated histones remain associated with DNA through replication. Cell 2012; 150: 922-933.

29 Petruk S, Black KL, Kovermann SK, Brock HW, Mazo A. Stepwise histone modifications are mediated by multiple enzymes that rapidly associate with nascent DNA during replication. Nat Commun 2013; 4: 2841.

30 Markaki Y, Smeets D, Cremer M, Schermelleh L. Fluorescence in situ hybridization applications for superresolution 3D structured illumination microscopy. Methods Mol Biol 2013; 950: 43-64.

31 Wang F, Higgins JM. Histone modifications and mitosis: countermarks, landmarks, and bookmarks. Trends Cell Biol 2013; 23: 175-184.

32 Verma S, Tian X, LaFrance L et al. Identification of potent, selective, cell-active inhibitors of the histone lysine methyltransferase EZH2. ACS Med Chem Lett 2012; 3: 1091-1096.

33 Beguelin W, Popovic R, Teater M et al. EZH2 is required for germinal center formation and somatic EZH2 mutations promote lymphoid transformation. Cancer Cell 2013; 23: 677-692.
34 Steffen PA, Ringrose L. What are memories made of? How Polycomb and Trithorax proteins mediate epigenetic memory. Nat Rev Mol Cell Biol 2014; 15: 340-356.

35 Vagnarelli P. Mitotic chromosome condensation in vertebrates. Exp Cell Res 2012; 318: 1435-1441.

36 Vagnarelli P. Chromatin reorganization through mitosis. Adv Protein Chem Struct Biol 2013; 90: 179-224.

37 Rieder D, Trajanoski Z, McNally JG. Transcription factories. Front Genet 2012; 3: 221.

38 Li HB, Ohno K, Gui H, Pirrotta V. Insulators target active genes to transcription factories and polycomb-repressed genes to polycomb bodies. PLoS Genet 2013; 9: e1003436.

39 Naumova N, Imakaev M, Fudenberg G et al. Organization of the mitotic chromosome. Science 2013; 342: 948-953.

40 Beck SA, Falconer E, Catching A, Hodgson JW, Brock HW. Cell cycle defects in polyhomeotic mutants are caused by abrogation of the DNA damage checkpoint. Dev Biol 2010; 339: 320-328.

41 Schneider I. Cell lines derived from late embryonic stages of Drosophila melanogaster. J Embryol Exp Morphol 1972; 27: 353-365.

42 Kruhlak MJ, Hendzel MJ, Fischle W et al. Regulation of global acetylation in mitosis through loss of histone acetyltransferases and deacetylases from chromatin. $J$ Biol Chem 2001; 276: 38307-38319.

43 Ali SA, Zaidi SK, Dobson JR et al. Transcriptional corepressor TLE1 functions with Runx2 in epigenetic repression of ribosomal RNA genes. Proc Natl Acad Sci USA 2010; 107: 4165-4169.

44 Haraguchi T, Kaneda T, Hiraoka Y. Dynamics of chromosomes and microtubules visualized by multiplewavelength fluorescence imaging in living mammalian cells: effects of mitotic inhibitors on cell cycle progression. Genes Cells 1997; 2: 369-380.

45 Cooper S, Iyer G, Tarquini M, Bissett P. Nocodazole does not synchronize cells: implications for cell-cycle control and whole-culture synchronization. Cell Tissue Res 2006; 324: 237-242.

46 Gemkow MJ Part II. Fly-FISHing: A Protocol to Localize Single Copy Genes inside the Nucleus in Whole Mount Embryos, Institut national de la santé et de la recherche médicale: Paris, France, 2001.

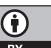

This work is licensed under a Creative Commons Attribution 4.0 International License. The images or other third party material in this article are included in the article's Creative Commons license, unless indicated otherwise in the credit line; if the material is not included under the Creative Commons license, users will need to obtain permission from the license holder to reproduce the material. To view a copy of this license, visit http://creativecommons.org/licenses/by/4.0/

(C) The Author(s) 2016 